\title{
Contact Position Estimation of Image-based Areal Touch Sensor using Artificial Neural Network
}

\author{
Jong Il Lee $e^{\mathrm{a}, \mathrm{b}}$, Su Woong Lee ${ }^{\mathrm{a}}$, Bo Ram Cho ${ }^{\mathrm{a}}$, Ki Hoon Kwon ${ }^{\mathrm{b}}$, Hyun Min $\mathrm{Oh}^{\mathrm{b}}$, Min Young Kim, \\ ${ }^{a}$ Technology Convergence R\&BD Group, Korea Institute of Industrial Technology(KITECH), Daegu, Korea

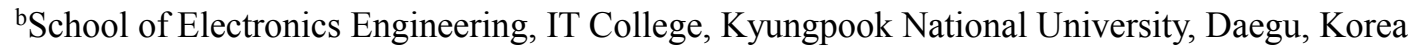 \\ *Corresponding Author: minyoung.kim2@gmail.com
}

\begin{abstract}
In this paper, we propose an artificial neural network fitting model to estimate contact position an image-based areal touch sensor (IATS) with soft physical contact. First, the principle of the proposed artificial neural network fitting model for contact position estimation is described. Then, the structure of the IATS for verifying the algorithm is described. Second, an experiment was conducted to verify the model. Experimental data was obtained and analyzed for accuracy. The $\mathrm{x}$-axis and $\mathrm{y}$-axis error value were found to be $1.84 \mathrm{~mm}$ and $0.9 \mathrm{~mm}$, respectively, while the depth error value was found to be $0.2 \mathrm{~mm}$.
\end{abstract}

Keywords: intelligent robot, artificial neural network, contact sensor, image processing, soft material.

\section{Introduction}

Apart from electronic devices, such as smartphones and personal computers (PC), human-friendly intelligent devices, such as wearable devices and humanoid robots have become essential products around $\mathrm{us}^{(1)}$. A wearable device, which is a small and lightweight new generation intelligent device worn on human body or clothes for portable use during movements, can be beneficial to human health by learning variable human biometric data and delivering appropriate information ${ }^{(2,3,4)}$. In addition, there are humanoid robots that perform difficult tasks in place of humans or intelligent robots that are used in industrial fields ${ }^{(5,6)}$. These devices often collaborate with humans to support them in a variety of fields. Thus, it is necessary to exchange information quickly, accurately, and reliably between humans and intelligent devices; for this reason, sensors are required as an interface.
Sensors are employed to convert human's five senses into mechanical or electronic signals ${ }^{(7)}$. There are various types of sensors, such as image sensor, touch sensor, pressure sensor, and position sensor. In recent years, information exchange through touch has become prevalent and many sensors related to touch have been developed ${ }^{(8)}$. Most sensors are made by chemical or electronic processing methods based on specific semi-conductor materials. A resistive touch sensor is a plate-shaped structure of conductive elastic rubber mixed with carbon powder or metal on silicone rubber ${ }^{(9)}$. It extracts contact position from changes in resistance due to applied force. A piezoelectric touch sensor is a structure using piezoelectric film, such as polyvinylidene fluoride ${ }^{(10)}$. It extracts contact position based on the level of flexibility of pressure film according to the deformation shape of the piezoelectric film due to applied force. Apart from the above sensors, other types of touch sensors, such as capacitive touch sensor can be found ${ }^{(11)}$. These touch sensors require capacitive coupling to accurately detect touch position. On the other hand, they require the design of complex circuits or fabrication processes. A touch sensor has several drawbacks due to inherent characteristics of semi-conductors, such as rigid physical property, weak durability, and degraded compatibility ${ }^{(12)}$. This study proposes an image-based areal touch sensor (IATS) ${ }^{(13,14)}$ using soft material and image sensor. We propose a contact position estimation model based on artificial neural network. In Chapter 2, the structure of the IATS and a process to create the artificial neural network model are explained. In Chapter 3, a learning process for the artificial neural network and results of contact position estimation of the developed model, as well as performance evaluation through data analysis are described. Finally, in Chapter 4, conclusions are presented. 


\section{IATS and ANN Model}

\subsection{Structure of IATS}

The IATS has a touch area made from soft materials, such as artificial leather or urethane rubber. It also has a circle marker to recognize when a change in shape occurs due to physical touch, and an image sensor to capture the change in shape. Therefore, this touch sensor is a new concept with various features that are different from existing touch sensors. Figure 1 shows the IATS used to validate the proposed model in this study. The IATS consists of soft fabric $(3,4)$, to which several circle markers are attached at regular intervals to function as the touch area, LED (2) that supplies light within the sensor, and a camera module (1) to capture images of the marker. Once a user presses the touch area of the sensor, a camera attached to the lower end receives real-time images of the circle marker, which is moved by an external force. The IATS is thought to have various advantages if the size of hardware can be improved, that is, become thinner by adopting small-size image sensor and wide-range angle lens. It can be applicable to soft 3D input device, soft pressure distribution sensor as well as soft sensor for human-robot coexistence or collaboration.

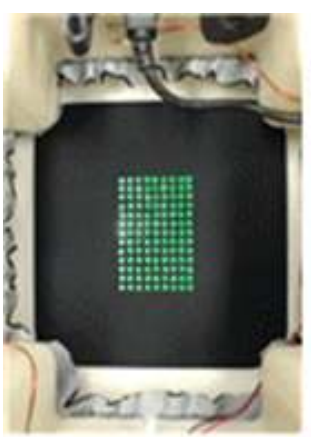

(A)

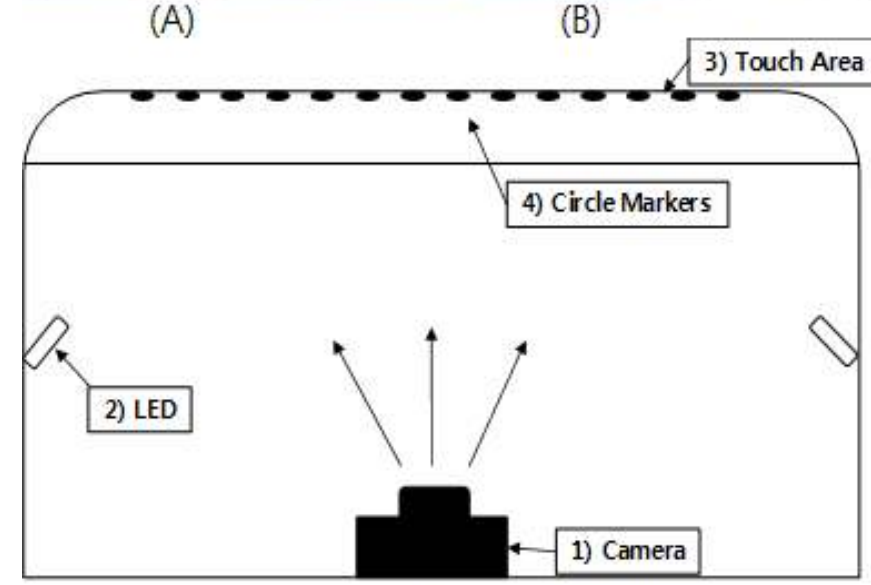

(C)

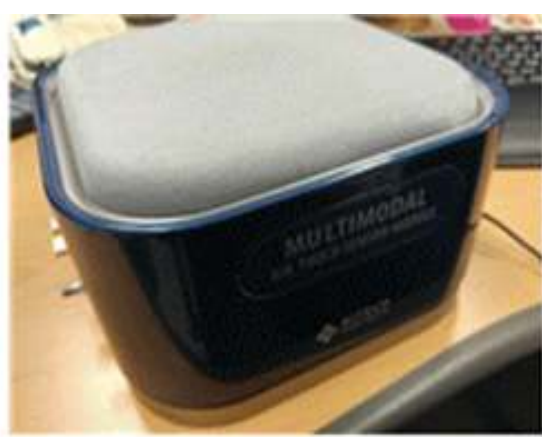

(B)

1) Camera
Fig. 1. Structure of IATS.

(A: inside, B: outside, C: structure chart)
Table 1. Comparison of existing touch sensor and IATS.

\begin{tabular}{|c|c|c|}
\hline $\begin{array}{c}\text { Conversion } \\
\text { method }\end{array}$ & $\begin{array}{c}\text { Converts physical } \\
\text { signals to } \\
\text { electromagnetic data }\end{array}$ & $\begin{array}{c}\text { Converts physical signals } \\
\text { to image data }\end{array}$ \\
\hline $\begin{array}{c}\text { Material } \\
\text { composition }\end{array}$ & $\begin{array}{c}\text { Composed of special } \\
\text { material }\end{array}$ & $\begin{array}{c}\text { Composed of soft } \\
\text { material }\end{array}$ \\
\hline Characteristics & $\begin{array}{c}\text { Determines functions } \\
\text { according to material }\end{array}$ & $\begin{array}{c}\text { Determines various } \\
\text { functions according to } \\
\text { S/W }\end{array}$ \\
\hline Feature & Single function & $\begin{array}{c}\text { Various functions, } \\
\text { versatile }\end{array}$ \\
\hline
\end{tabular}

The received images are pre-processed and digitized to estimate contact position through the artificial neural network model created through learning. Table 1 compares the features of an existing touch sensor with that of the IATS.

\subsection{Extraction of learning data set}

It is necessary to perform a data extraction process for learning in order to develop the artificial neural network model. Once images obtained through the camera are inputted, features are extracted using an algorithm for preprocessing to acquire accurate contact position, as well as shortening the processing time. Figure 2 shows a flow chart for the preprocessing algorithm. To shorten the processing time, a three-channel RGB image is first converted into a single channel image. In general, a single channel image is implemented with the mean of RGB values. However, since the color of the circle marker attached to the IATS is green, a single channel image is created with only green channel among the RGB channels to obtain a sharp contrast between the background and the marker. Next, morphology processing is performed to remove noise. Noise removal and images with single channel should have binarization transform to separate the background from the maker. To do this, a threshold value in terms of brightness is determined using the Otsu algorithm ${ }^{(15,16)}$. The Otsu algorithm searches a threshold value in terms of brightness of inputted images. It finds a threshold value between two classes that minimizes dispersion inside a class or maximizes dispersion between classes when image pixels are classified into two types of classes based on histogram distribution. Since the inner structure of the IATS is closed, it is significantly affected by light. When a fixed threshold is used, it is difficult to accurately detect a marker moved by an external force. 


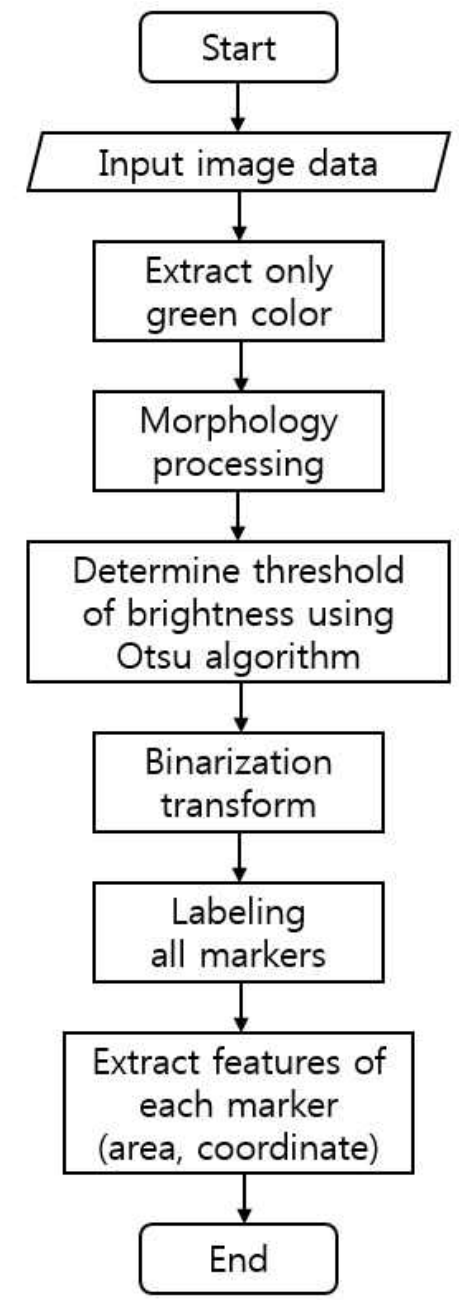

Fig. 2. Preprocessing algorithm for feature extraction.

Thus, if a threshold value that is changed according to circumstance using the Otsu algorithm is used to perform binarization transform, the background and marker can be accurately separated. Next, features (area, x/y-axis coordinate) of each marker can be detected by individualizing all markers through labeling ${ }^{(17-19)}$. Once the above processes are performed, a single learning data set can be produced.

\subsection{Fitting by artificial neural network}

An artificial neural network, such as deep learning has been widely-used in a structure where machine learning is required for complex pattern recognition or prediction that shows a correlation and fitting between input and output data, as well as having complex functional relationships while depending on a large amount of learning data ${ }^{(20-22)}$. The IATS also aims to estimate contact position using images, and its mid-process is quite complex. When a touch occurs in a specific position, contact position should be through inputted images. To do this, the correlation between

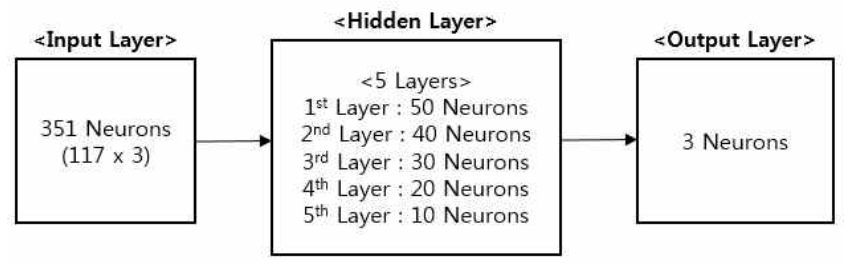

Fig. 3. Structure of neural network

input and output data can be established by means of fitting using artificial neural network. Figure 3 shows a structure of the artificial neural network used in this study. It consists of five hidden layers and one output layer to increase fitting performance, and the learning time was shortened using the Levenberg-Marquardt (LM) back-propagation algorithm, which was optimized for artificial neural network learning ${ }^{(23)}$. The artificial neural network model created through learning can estimate contact position and depth using input data.

\section{Learning and Experiment}

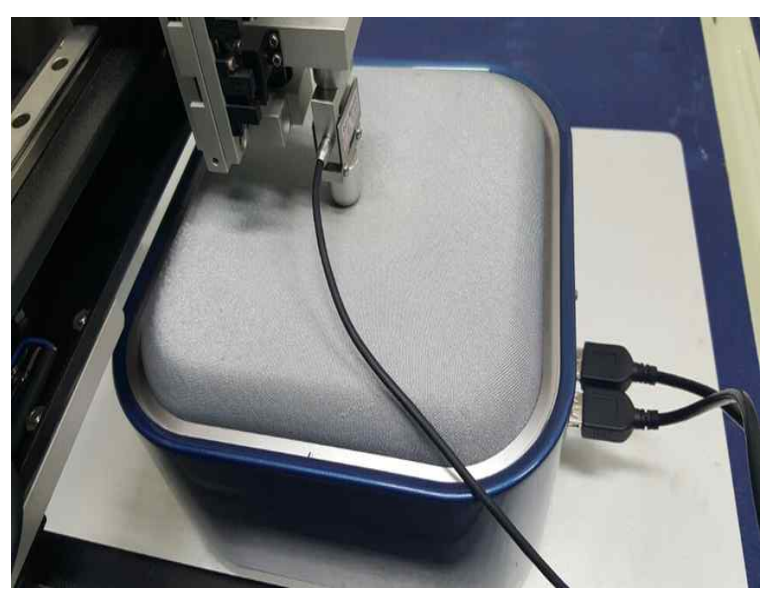

Fig. 4. Experimental setup of 3-axis linear motor stage.

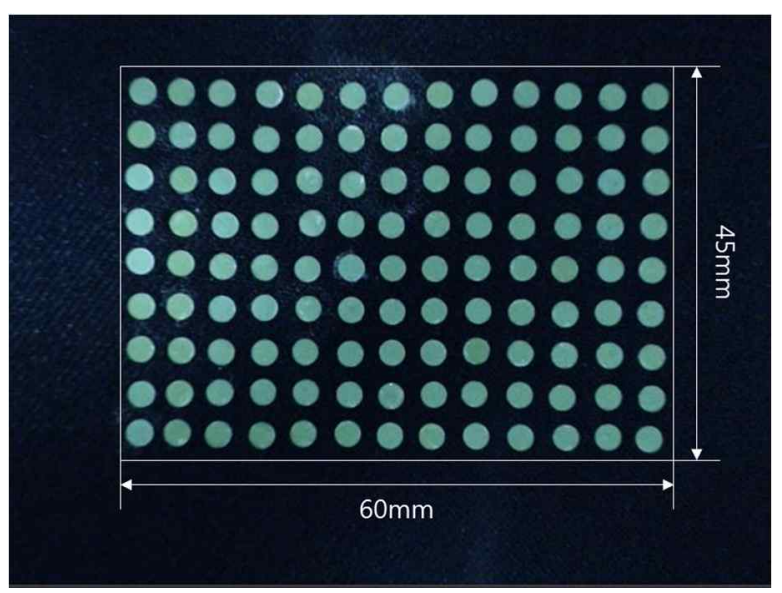

Fig. 5. Actual marker region. 
Figure 4 shows the experimental setup used in this study. The setup consists of 3-axis linear motor stage to extract learning data through a touch. A touch can be applied to an accurate position using experimental equipment. Figure 5 shows a marker region attached to the inside of the IATS. The number of markers was 117 . The first marker located in the left upper end was set to a relative coordinate of 0,0 $(\mathrm{mm})$, and the last marker located in the right lower end was set to a relative coordinate of $60,45(\mathrm{~mm})$. A total of 256 learning data sets can be created if touches were made in the $\mathrm{X}$-axis with $4 \mathrm{~mm}$ increment 16 times, and in the Y-axis with $3 \mathrm{~mm}$ increment 16 times.

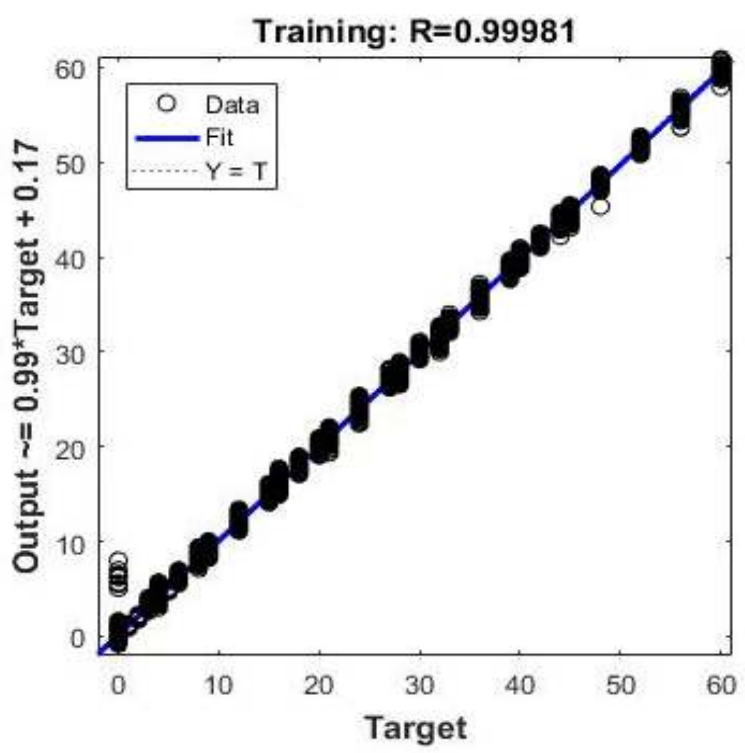

Fig. 6. Training data.

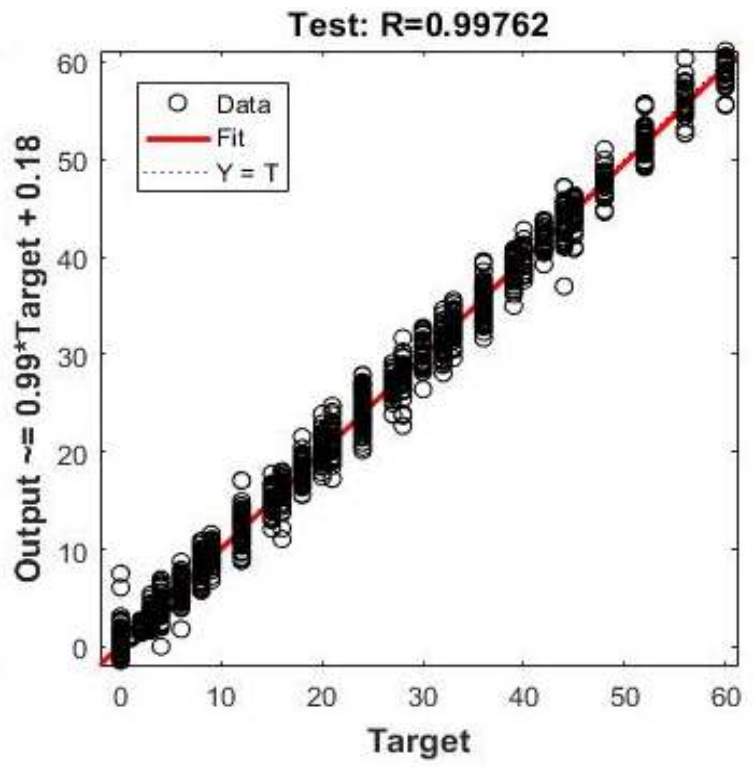

Fig. 7. Testing data.
Furthermore, learning data sets were created by differentiating the depth since the area and coordinate of all markers were different if the same position is touched according to the depth. Through the above procedure, learning datasets were created, and the number of input data neurons was set to 351 , and the number of target data neurons was set to 3 , thereby creating the artificial neural network model through learning. Figures 6 and 7 show fitting results of training and testing data. In the figures, $\mathrm{R}$ refers to a relationship between output and target data. If $\mathrm{R}$ is close to 1 , the relationship between the two data sets is close to a linear relationship. Thus, the figures show that fitting was properly implemented through learning. The learning time to create the artificial neural network model was approximately $13 \mathrm{~h}$ and $20 \mathrm{~min}$. However, the processing time of input and output in the model created through learning was $0.0058 \mathrm{sec}$.

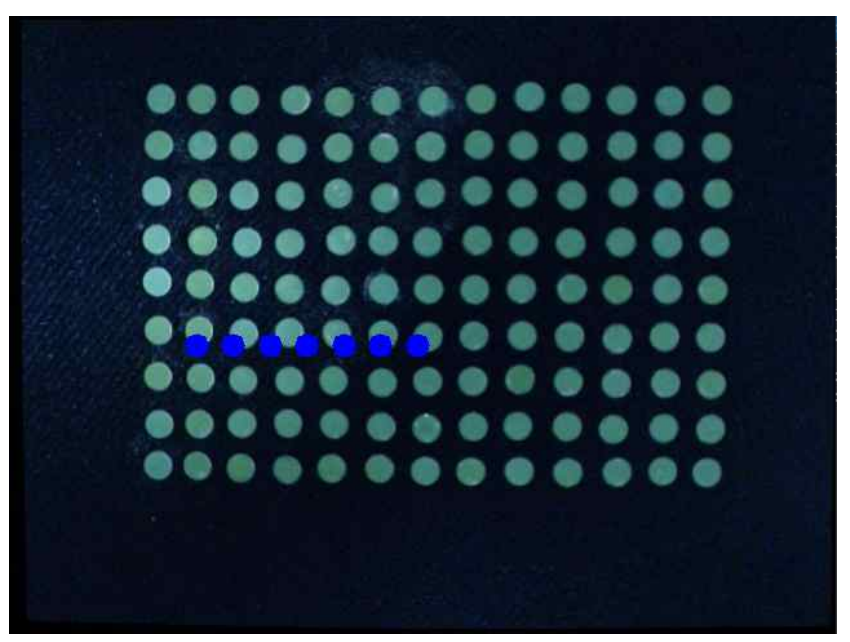

Fig. 8. Actual contact position.

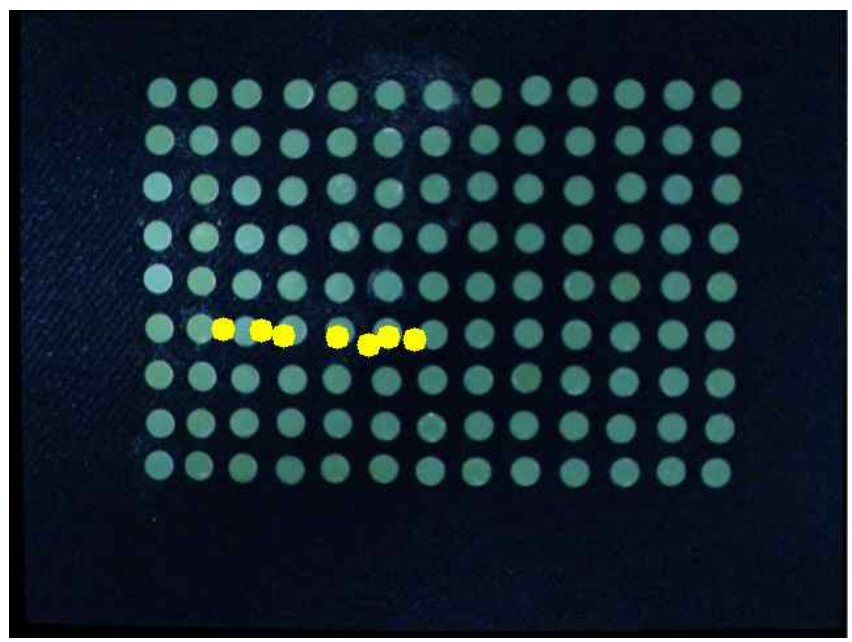

Fig. 9. Estimated contact position. 
Next, the accuracy of the artificial neural network model was verified. While touching with constant movements in the horizontal or vertical direction based on an arbitrary reference position, the accuracy in terms of the coordinate and the depth was analyzed. Figures 8 and 9 show the actual contact positions, and contact positions estimated using the model. Based on the relative coordinate 4, 30 $(\mathrm{mm})$, the results of the contact position that was moved by $4 \mathrm{~mm}$ in the right direction in the $\mathrm{X}$-axis are shown. Table 2 presents numerical data and errors between the two data sets. The mean error in the $\mathrm{X}$-axis coordinate was $1.84 \mathrm{~mm}$, and that in the Y-axis coordinate was $0.9 \mathrm{~mm}$. The mean error in terms of the depth was $0.2 \mathrm{~mm}$.

Figure 10 and Table 3 show the actual contact position and the estimated contact position when random contact at any position. In addition, it can be seen that the size of the circle indicating the contact position is changed in size of the depth. Therefore, it is easy to visually ascertain the difference in depth.

Table 2. Numerical data and error value.

\begin{tabular}{|l|l|l|}
\hline \multicolumn{1}{|c|}{$\begin{array}{c}\text { Actual contact } \\
\text { position }\end{array}$} & \multicolumn{1}{|c|}{$\begin{array}{c}\text { Estimated } \\
\text { contact position }\end{array}$} & \multicolumn{1}{|c|}{ Error value } \\
\hline X: $4 \mathrm{~mm}$ & X: $6.7 \mathrm{~mm}$ & X: $2.7 \mathrm{~mm}$ \\
Y: $30 \mathrm{~mm}$ & Y: $28.2 \mathrm{~mm}$ & Y: $1.8 \mathrm{~mm}$ \\
Depth: $4 \mathrm{~mm}$ & Depth: $3.75 \mathrm{~mm}$ & Depth: $0.25 \mathrm{~mm}$ \\
\hline X: $8 \mathrm{~mm}$ & X: $10.8 \mathrm{~mm}$ & X: $2.8 \mathrm{~mm}$ \\
Y: $30 \mathrm{~mm}$ & Y: $28.5 \mathrm{~mm}$ & Y: $1.5 \mathrm{~mm}$ \\
Depth: $4 \mathrm{~mm}$ & Depth: $3.86 \mathrm{~mm}$ & Depth: $0.14 \mathrm{~mm}$ \\
\hline X: $12 \mathrm{~mm}$ & X: $13.2 \mathrm{~mm}$ & X: $1.2 \mathrm{~mm}$ \\
Y: $30 \mathrm{~mm}$ & Y: $29.1 \mathrm{~mm}$ & Y: $0.9 \mathrm{~mm}$ \\
Depth: $4 \mathrm{~mm}$ & Depth: $4.11 \mathrm{~mm}$ & Depth: $0.11 \mathrm{~mm}$ \\
\hline X: $16 \mathrm{~mm}$ & X: $18.9 \mathrm{~mm}$ & X: $2.9 \mathrm{~mm}$ \\
Y: $30 \mathrm{~mm}$ & Y: $29.2 \mathrm{~mm}$ & Y: $0.8 \mathrm{~mm}$ \\
Depth: $4 \mathrm{~mm}$ & Depth: $4.15 \mathrm{~mm}$ & Depth: $0.15 \mathrm{~mm}$ \\
\hline X: $20 \mathrm{~mm}$ & X: $22.2 \mathrm{~mm}$ & X: $2.2 \mathrm{~mm}$ \\
Y: $30 \mathrm{~mm}$ & Y: $30.2 \mathrm{~mm}$ & Y: $0.2 \mathrm{~mm}$ \\
Depth: $4 \mathrm{~mm}$ & Depth: $4.21 \mathrm{~mm}$ & Depth: $0.21 \mathrm{~mm}$ \\
\hline X: $24 \mathrm{~mm}$ & X: $24.3 \mathrm{~mm}$ & X: $0.3 \mathrm{~mm}$ \\
Y: $30 \mathrm{~mm}$ & Y: $29.2 \mathrm{~mm}$ & Y: $0.8 \mathrm{~mm}$ \\
Depth: $4 \mathrm{~mm}$ & Depth: $4.28 \mathrm{~mm}$ & Depth: $0.28 \mathrm{~mm}$ \\
\hline X: $28 \mathrm{~mm}$ & X: $27.2 \mathrm{~mm}$ & X: $0.8 \mathrm{~mm}$ \\
Y: $30 \mathrm{~mm}$ & Y: $29.5 \mathrm{~mm}$ & Y: $0.5 \mathrm{~mm}$ \\
Depth: $4 \mathrm{~mm}$ & Depth: $4.3 \mathrm{~mm}$ & Depth: $0.3 \mathrm{~mm}$ \\
\hline
\end{tabular}

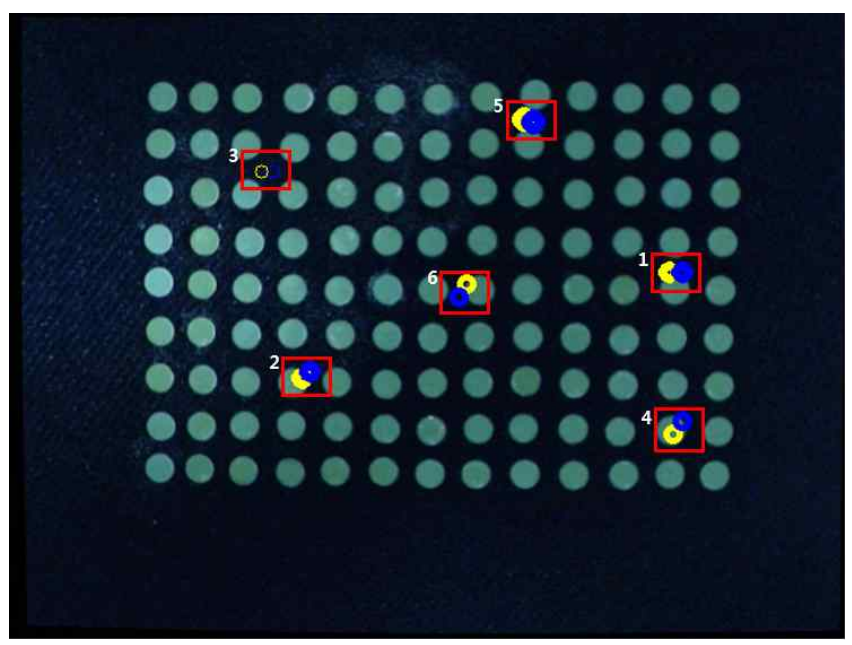

Fig. 10. Random contact at any position.

Table 3. Numerical data of random contact.

\begin{tabular}{|c|c|c|}
\hline & Actual contact position & $\begin{array}{c}\text { Estimated contact } \\
\text { position }\end{array}$ \\
\hline 1 & $\begin{array}{l}\text { X: } 56 \mathrm{~mm} \\
\text { Y: } 21 \mathrm{~mm} \\
\text { Depth: } 4 \mathrm{~mm}\end{array}$ & $\begin{array}{l}\text { X: } 54.5 \mathrm{~mm} \\
Y: 21.1 \mathrm{~mm} \\
\text { Depth: } 3.8 \mathrm{~mm}\end{array}$ \\
\hline 2 & $\begin{array}{l}\text { X: } 16 \mathrm{~mm} \\
\text { Y: } 33 \mathrm{~mm} \\
\text { Depth: } 4 \mathrm{~mm}\end{array}$ & $\begin{array}{l}\mathrm{X}: 15.1 \mathrm{~mm} \\
\mathrm{Y}: 33.7 \mathrm{~mm} \\
\text { Depth: } 3.86 \mathrm{~mm}\end{array}$ \\
\hline 3 & $\begin{array}{l}\mathrm{X}: 12 \mathrm{~mm} \\
Y: 9 \mathrm{~mm} \\
\text { Depth: } 1 \mathrm{~mm}\end{array}$ & $\begin{array}{l}\mathrm{X}: 10.7 \mathrm{~mm} \\
Y: 8.98 \mathrm{~mm} \\
\text { Depth: } 1.1 \mathrm{~mm}\end{array}$ \\
\hline 4 & $\begin{array}{l}\text { X: } 56 \mathrm{~mm} \\
Y: 39 \mathrm{~mm} \\
\text { Depth: } 2 \mathrm{~mm}\end{array}$ & $\begin{array}{l}\text { X: } 54.99 \mathrm{~mm} \\
\text { Y: } 40.43 \mathrm{~mm} \\
\text { Depth: } 2.13 \mathrm{~mm}\end{array}$ \\
\hline 5 & $\begin{array}{l}\mathrm{X}: 40 \mathrm{~mm} \\
Y: 3 \mathrm{~mm} \\
\text { Depth: } 5 \mathrm{~mm}\end{array}$ & $\begin{array}{l}\mathrm{X}: 38.96 \mathrm{~mm} \\
\text { Y: } 2.7 \mathrm{~mm} \\
\text { Depth: } 5.1 \mathrm{~mm}\end{array}$ \\
\hline 6 & $\begin{array}{l}\mathrm{X}: 32 \mathrm{~mm} \\
\mathrm{Y}: 24 \mathrm{~mm} \\
\text { Depth: } 3 \mathrm{~mm}\end{array}$ & $\begin{array}{l}\mathrm{X}: 32.8 \mathrm{~mm} \\
\mathrm{Y}: 22.4 \mathrm{~mm} \\
\text { Depth: } 3.08 \mathrm{~mm}\end{array}$ \\
\hline
\end{tabular}

\section{Conclusions}

This study proposed an artificial neural network learning and model for contact position estimation using IATS. Contact position was estimated by substituting feature data with an artificial neural network model after preprocessing of input images.

The artificial neural network fitting model using the proposed IATS can perform contact position estimation only within the marker region. Therefore, it is planned to 
further improve contact position estimation in a wider area by increasing the number of markers and the region by means of miniaturization of the IATS in the future. Furthermore, this study found that the functional relationship was relatively simple and the processing speed was fast with high accuracy compared with touch position estimation using image processing in previous studies. Thus, if the error in the touch position can be reduced to as low as possible with improvements in the training algorithm and appropriate parameter setup, the proposed contact position estimation can be combined with other intelligent systems. To verify the accuracy of the proposed method, the comparison with a conventional sensor such as capacitance type is also one of our future work.

\section{Acknowledgment}

This work was supported by the KITECH R\&D Program of the Development of Soft Robotics Technology for Human-Robot Coexistence Care Robots and DGIST R\&D Program of the Ministry of Science, ICT and Future Planning (17-ST-01) and the National Research Foundation of Korea (NRF) grant funded by the Korea government (MSICT) (NRF-2016M2 A2A4A04913462).

\section{References}

(1) F. Sarah and W. Philip : "Industrial robot ethics: facing the challenges of human-robot collaboration in future manufacturing systems", A World with Robots : International Conference on Robot Ethics : ICRE 2015", pp. 159-169, 2017

(2) S. B. Schorr and A. Okamura : "Three-dimensional skin deformation as force substitution: Wearable device design and performance during haptic exploration of virtual environments", IEEE Transactions on Haptics, Vol. pp, no. 99, pp. 1-1, 2017.

(3) J. Rossiter, E. Knoop and Y. Nakamura : "Affective Touch and Low Power Artificial Muscles for Rehabilitative and Assistive Wearable Soft Robotics", Wearable Robotics : Challenges and Trends, Vol. 16, pp. 101-106, 2016.

(4) N. David : "Wearable Smart Device Incorporating Real-Time Clock Module and Alcohol Sensor", The International Conference on Design and Technology, pp. 328-333, 2016

(5) J. Y. Aaron and P. F. Daniel : "State of the Art and
Future Directions for Lower Limb Robotic Exoskeletons", IEEE Transactions on Neural Systems and Rehabilitation Engineering, Vol. 25, pp. 171-182, 2016.

(6) L. Wu, M. J. Andrade, L. K. Saharan, R. S. Rome, R. H. Baughman and Y. Tadesse : "Compact and low-cost humanoid hand powered by nylon artificial muscles", Bioinspiration \& Biomimetics, Vol. 12, no. 2, pp. $026004,2017$.

(7) S. Kanaparthi and S. Badhulika : "Low cost, flexible and biodegradable touch sensor fabricated by solvent-free processing of graphite on cellulose paper", Sensors and Actuators B: Chemical, Vol. 242, pp. 857-864, 2017

(8) L. K. Lee, S. M. Park, H. C. Kim, Y. K. Kwon, S. H. Kang and B. W. Choi : "An intelligence embedding quadruped pet robot with sensor fusion", Journal of Control, Automation, and System Engineering, Vol. 11, no. 4, pp. 314-321, 2005.

(9) H. J. Kim, J. B. Park, Y. H. Joo and W. Jang : "Implementation of a Thin Multi-touch Sensor Using Resistive Tactile Sensing Technology", Journal of Institute of Control, Robotics and Systems, pp. 690-692, 2011.

(10) R. S. Dahiya, G. Metta, M. Valle, A. Adami and L. Lorenzelli : "Piezoelectric oxide semiconductor field effect transistor touch sensing devices", Applied Physics Letters, Vol. 95, 2009.

(11) K. S. Abhishek, L. C. F. Qubeley and D. Ho : "Glove-based hand gesture recognition sign language translator using capacitive touch sensor", 2016 IEEE International Conference on Electron Devices and Solid-State Circuits, pp. 334-337, 2016.

(12) J. I. Lee and K. Sato : "Polymer based slim tactile sensor: Optimal design and new fabrication method", Journal of Institute of Control, Robotics and Systems, Vol. 17, pp. 131-134, 2010.

(13) S. W. Lee, S. O. Kwon, Y. W. Kim and K. W. Lee : “A method of vertical and horizontal force estimation by using air-filled material and camera for soft physical human-robot interaction: fundamental experiments", Advanced Robotics, Vol. 30, no. 5, pp. 352-359, 2016.

(14) J. I. Lee, H. M. Oh, S. W. Lee and M. Y. Kim : "Image processing algorithms for touch-position estimation of an image-based areal touch sensor", Journal of Institute of Control, Robotics and Systems, Vol. 23, no. 6, 2017.

(15) N. Wang, X. Li, and X. Chen : "Fast three-dimensional 
Otsu thresholding with shuffled frog-leaping algorithm", Pattern Recognition, Vol. 31, pp. 1809-1815, 2010.

(16) T. Kurita, N. Otsu, and N. Abdelmalek : "Maximum likelihood thresholding based on population mixture models", Pattern Recognition, Vol. 25, pp. 1231-1240, 1992.

(17) B. Paul and M. Christopher: "The theory and practice of Bayesian image labeling", International Journal of Computer Vision, Vol. 4, pp. 185-210, 1990.

(18) E. Saber, Y. Xu, and A. M. Tekalp : "Partial shape recognition by sub-matrix matching for partial matching guided image labeling”, Pattern Recognition, Vol. 38, pp. 1560-1573, 2005.

(19) S. G. Dellepiane, F. Fontana, and G. L. Vernazza : "Nonlinear image labeling for multivalued segmentation", IEEE Transactions on Image Processing, Vol. 5, pp. 429-446, 2002.

(20) N. Cohen, O. Sharir and A. Shashua : "On the Expressive Power of Deep Learning : A Tensor Analysis", 29 ${ }^{\text {th }}$ Annual Conference on Learning Theory, Vol. 49, pp. 698-728, 2016

(21) N. Murata, S. Yoshizawa and S. Amari : "Network information criterion-determining the number of hidden units for an artificial neural network model", IEEE Transactions on Neural Networks, Vol. 5, no. 6, pp. 865-872, 1994

(22) S. C. B. Lo, H. P. Chan, J. S. Lin, H. Li, M. T. Freedman and S. K. Mun : "Artificial convolution neural network for medical image pattern recognition", Elsevier(Neural Networks), Vol. 8, no. 7-8, pp. 1201-1214, 1995

(23) A. Mohammed and S. Zyad : "Face Recognition Based on Haar Wavelet Transform and Principal Component Analysis via Levenberg-Marquardt Backpropagation Neural Network", European Journal of Scientific Research, Vol. 42, no. 1, pp. 25-31, 2010. 